\title{
Optimised sample preparation of synovial fluid for detection of Chlamydia trachomatis DNA by polymerase chain reaction
} Jens G Kuipers, Lars Nietfeld, Ute Dreses-Werringloer, Lars Koehler,
Juergen Wollenhaupt, Henning Zeidler, Michael Hammer

\begin{abstract}
Objective-To optimise sample preparation of synovial fluid for Chlamydia trachomatis (CT) specific polymerase chain reaction (PCR).

Methods-Serial dilutions of purified CT elementary bodies in synovial fluid were prepared. The synovial fluid pellet was processed by eight different methods of sample preparation. Then samples were analysed by CT specific PCR. The sensitivity of PCR was the basis of ranking of the eight different methods.

Results-Highest sensitivity was achieved by methods including an additional step of DNA isolation. Additional extraction of protein and polysaccharides by cetyltrimethylammonium bromide (CTAB) increased sensitivity. Addition of hyaluronidase did not increase sensitivity of QIAEX-DNA extraction but was necessary, however, before phenol-chloroformDNA extraction.

Conclusions-The method of synovial fluid sample preparation significantly influences the sensitivity of subsequent PCR. Additional DNA isolation and extraction of PCR inhibitors by CTAB led to higher sensitivity.

(Ann Rheum Dis 1999;58:103-108)
\end{abstract}

Division of

Rheumatology,

Department of

Internal Medicine and

Dermatology,

Hannover Medical

School, Hannover,

Germany

J G Kuipers

L Nietfeld

U Dreses-Werringloer

L Koehler

J Wollenhaupt

H Zeidler

Department of

Rheumatology,

Nordwestdeutsches

Rheumazentrum, St

Josef-Stift,

Sendenhorst, Germany

M Hammer

Correspondence to:

Dr J Kuipers, Division of

Rheumatology, Hannover

Medical School, 30623

Hannover, Germany.

Accepted for publication 13 October 1998
Reactive arthritis or Reiter's syndrome is an aseptic synovialitis occurring after or during extra-articular infections. Chlamydia trachoma$t i s$, the most common agent of sexually transmitted disease in developed countries, ${ }^{1}$ represents one of the most important causes of reactive arthritis. Although $C$ trachomatis (CT) could not be cultured from the synovial fluid from patients with CT induced reactive arthritis, chlamydial antigen, rRNA, and DNA were detected in the inflamed joint. ${ }^{2-5}$ Furthermore it was demonstrated recently that viable, metabolically active although non-culturable CT organisms persist intra-articularly for several years. ${ }^{6} 7$

Intra-articular detection of the organism is crucial for correct diagnosis. Recently we compared several detection methods with polymerase chain reaction (PCR) for their sensitivity to detect CT in synovial fluid. PCR was found to be the most sensitive method. ${ }^{8}$ By now several reports have been published successfully using PCR for the detection of CT and other arthritis eliciting baceria such as borrelia or salmonella in synovial fluid. ${ }^{59}{ }^{10}$ To increase sensitiv- ity and validity the use of several PCRs with different targets, for example, chromosomal and plasmid DNA of one organism has been proposed.

Because of the low quantity of arthritis eliciting bacteria in the inflamed joints of reactive arthritis patients not only should the detection method be of the highest possible sensitivity but also sample preparation needs to be optimised before PCR.

To our knowledge no systematic analysis of the comparative performance of different sample preparations of synovial fluid for PCR has been reported.

In this study SF spiked with defined numbers of purified CT elementary bodies were processed using eight different sample preparations and analysed by CT specific PCR. An optimised method of processing synovial fluid for PCR was developed.

\section{Methods}

PREPARATION OF CHLAMYDIA TRACHOMATIS ELEMENTARY BODIES

$C$ trachomatis elementary bodies were prepared as described. ${ }^{11}$ In brief, infectious elementary bodies of $C$ trachomatis serovar K (UW/31/Cx; Washington Research Foundation, Seattle, WA, USA) were grown in HEp-2 cells (human larynx carcinoma epithelial cell line). Serovar $\mathrm{K}$ was chosen for analysis because it causes urogenital tract infections and has been shown to induce reactive arthritis. The organisms were purified in a discontinuous gradient of Urografin (Schering, Berlin, Germany) by ultracentrifugation as described. ${ }^{11}$ Purified elementary bodies were resuspended in $1 \mathrm{ml}$ of sucrose phosphate buffer $(0.01 \mathrm{M}$ sodium phosphate, $0.25 \mathrm{M}$ sucrose, $5 \mathrm{mM}$ L-glutamic acid, $\mathrm{pH}$ 7.2, all chemicals were from Sigma, St Louis, USA) and stored at $-80^{\circ} \mathrm{C}$. By titration on HEp-2 cells and subsequent indirect immunoperoxidase assay $4.8 \times 10^{6}$ inclusion forming units (IFU)/ml were determined. This stock of purified elementary bodies was 100-fold diluted, divided into aliquots, and kept at $-80^{\circ} \mathrm{C}$. For each assay one aliquot was thawed and diluted further in synovial fluid.

\section{IMMUNOFLUORESCENCE MICROSCOPY OF}

CHLAMYDIAL PARTICLES

Chlamydial major outer membrane protein (MOMP) was detected by direct immunofluorescence as described ${ }^{11}$ with a fluorescein conjugated murine monoclonal antibody (MAb) (MicroTrak, Syva, Palo Alto, CA, USA). All 


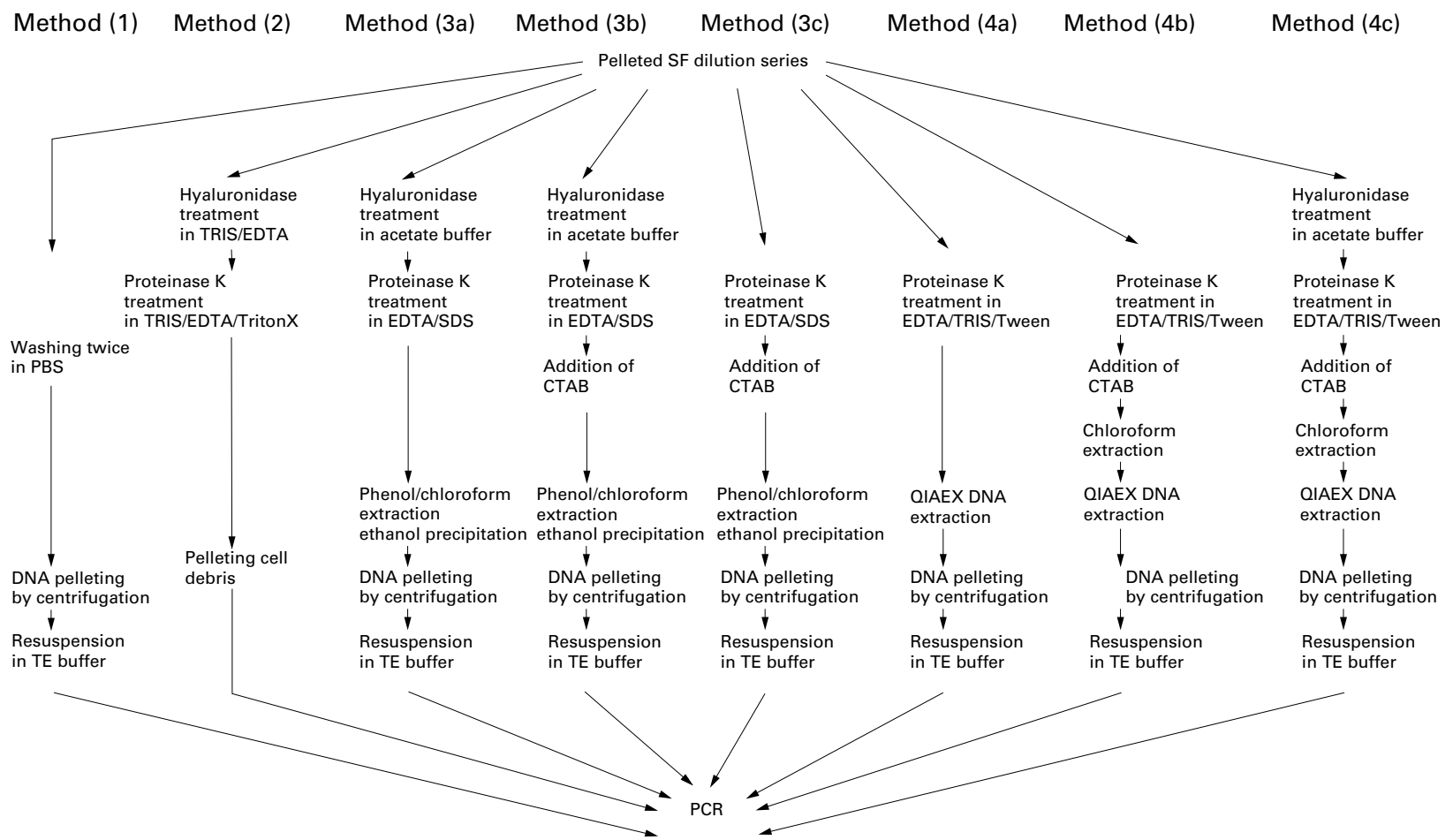

Figure 1 The eight different methods for processing of synovial fluid analysed in this study.

samples were screened with an epifluorescence microscope (Leitz, Wetzlar, Germany). Only brightly shining green particles were counted as fluorescent particles.

C TRACHOMATIS SERIAL DILUTIONS IN SYNOVIAL FLUID AND EIGHT DIFFERENT METHODS OF SAMPLE PREPARATION FOR PCR

Synovial fluid was obtained from rheumatoid arthritis (RA) patients with informed consent. These RA patients had no history of chlamydial infection and their synovial fluid was negative in several CT PCR reactions. The mean of the number of leucocytes and granulocytes in the synovial fluid samples used for dilutions series were $5900 / \mathrm{mm}^{3}$ (SD 8150) and $4012 /$ $\mathrm{mm}^{3}$ (SD 7476) respectively.

Purified $C$ trachomatis elementary bodies were 10 -fold serially diluted in synovial fluid. For each dilution synovial fluid from one patient with RA was used and analysed by the different methods. Two negative controls with no elementary bodies added were included in each experiment. Samples were then centrifuged at $60000 \mathrm{~g}$ for $30 \mathrm{~min}$ at $4^{\circ} \mathrm{C}$. The resulting pellet was then processed according to the eight different methods of sample preparation (fig 1).

Method (1)

Synovial fluid pellets were washed twice in phosphate buffered saline and resuspended in TRIS-EDTA (TE) buffer. ${ }^{13}$

Method (2)

Synovial fluid pellets were treated with $100 \mu \mathrm{l}$ of fresh bovine hyaluronidase solution (10 000 units/ml of buffer: $10 \mathrm{mM}$ TRIS $\mathrm{HCl}, 1 \mathrm{mM}$ EDTA, pH 6) for 2.5 hours at $37^{\circ} \mathrm{C}$. Cells were lysed by adding $200 \mu \mathrm{l}$ of fresh lysis buffer
(10 mM TRIS HCl, 1 mM EDTA, pH 8.3, 0.5 $\%$ Triton X-100, $500 \mu \mathrm{g} / \mathrm{ml}$ proteinase $\mathrm{K}$ ) and incubated in a shaker at $55^{\circ} \mathrm{C}$ overnight. Subsequently samples were heated at $95^{\circ} \mathrm{C}$ for 20 minutes. Cell debris was removed by centrifugation at $375 \mathrm{~g}$ for 10 minutes. ${ }^{5}$

Method (3a)

Synovial fluid pellets were pretreated with 150 $\mu \mathrm{l}$ of bovine hyaluronidase solution (1000 units in $0.1 \mathrm{M}$ acetate buffer) for 2.5 hours at $37^{\circ} \mathrm{C}$. Three hundred $\mu \mathrm{l}$ of lysis buffer $(20 \mathrm{mM}$ EDTA, $\mathrm{pH} 8,100 \mathrm{mM} \mathrm{NaCl}, 0.4 \%$ sodium dodecyl sulphate) were added followed by digestion with proteinase $\mathrm{K}(50 \mu \mathrm{g} / \mathrm{ml})$ at $55^{\circ} \mathrm{C}$ overnight. DNA was isolated by phenol/ chloroform extraction and ethanol precipitation and resuspended in TE buffer. ${ }^{9}$

Method (3b)

Similar to Method (3a). Additionally cetyltrimethylammonium bromide (CTAB) was added before phenol/chloroform extraction. ${ }^{14}$ Briefly, $\mathrm{NaCl}$ concentration was adjusted to 0.9 $\mathrm{M}$, then $10 \%(\mathrm{w} / \mathrm{v}) \mathrm{CTAB}$ in $0.7 \mathrm{M} \mathrm{NaCl}$ was added and incubated at $65^{\circ}$ for 10 minutes.

Method (3c)

Similar to Method (3b) without hyaluronidase pretreatment.

\section{Method (4a)}

The synovial fluid pellet was incubated in lysis buffer $(0.1 \mathrm{M} \mathrm{NaCl}, 1 \mathrm{mM}$ EDTA, $10 \mathrm{mM}$ TRIS HCl, $\mathrm{pH} 8,0.5 \%$ Tween 20 ) containing proteinase $\mathrm{K}(100 \mu \mathrm{g} / \mathrm{ml})$ at $56^{\circ} \mathrm{C}$ overnight. DNA was isolated using QIAEX gel extraction kit (Qiagen, Hilden, Germany) and resuspended in TE buffer. The QIAEX principle is based on the adsorption of DNA to silica gel 


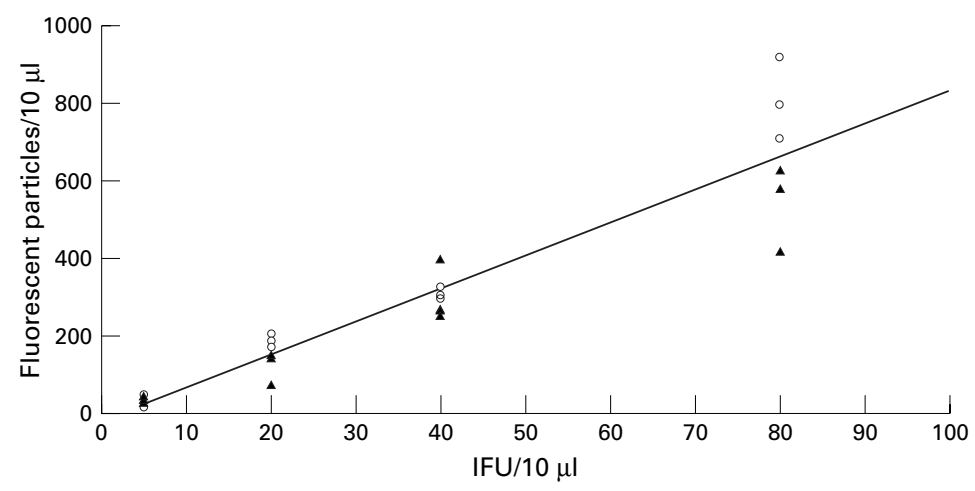

Figure 2 Number of fluorescent particles (depicted on the $y$ axis) per inclusion forming unit (IFU, shown on the $x$ axis). Dilutions of three randomly selected aliquots from the stock of purified $C$ trachomatis were analysed by immunofluorescence. Three slides per dilution per aliquot were analysed. The calculated curve for linear regression is shown (slope $=7.7$, $\left.r^{2}=0.82, p<0.0001\right)$.

particles in high salt. It was developed for the extraction and purification of DNA fragments from solubilised agarose gels.

Method (4b)

Similar to Method (4a) with an additional CTAB extraction before QIAEX DNA isolation. Briefly, $\mathrm{NaCL}$ concentration was adjusted to $0.9 \mathrm{M}$, then $10 \%(\mathrm{w} / \mathrm{v}) \mathrm{CTAB}$ in $0.7 \mathrm{M}$ $\mathrm{NaCl}$ added, incubated for $65^{\circ}$ for 10 minutes, followed by chloroform extraction.

Method (4c)

Synovial fluid pellets were pretreated with 150 $\mu 1$ of bovine hyaluronidase solution (1000 units in $0.1 \mathrm{M}$ acetate buffer) for 2.5 hours at $37^{\circ} \mathrm{C}$ and then processed as described for method (4a). The methods (1), (2), and (3a) have been published recently (method (1), $,^{13}(2),{ }^{5}$ and $\left.(3 a)^{9}\right)$. The other methods have been developed in our laboratory $(4 \mathrm{a}, 4 \mathrm{~b}, 4 \mathrm{c})$ or are modifications of method (3a) - that is, method (3b) and (3c). Three runs of comparative experiments with four different methods for each run were performed. In the second and third run the two best methods from the previous run were compared with their modifications.

DNA AMPLIFICATION BY PCR

The PCR used is specific for the $C$ trachomatis MOMP gene and has been described recently. ${ }^{8}$ As it was the aim of this study to analyse and optimise sample preparation of synovial fluid and not to analyse the sensitivity of different CT specific PCRs, only this MOMP gene specific PCR was used throughout this study. Briefly, target DNA was amplified for outer PCR through forty cycles (90 sec denaturation at $94^{\circ} \mathrm{C}, 90 \mathrm{sec}$ primer annealing at $55^{\circ} \mathrm{C}, 90$ sec primer extension at $72^{\circ} \mathrm{C}$ ) using $50 \mathrm{pmol}$ ct0 5 and ct06 for outer PCR in a $100 \mu \mathrm{l}$ volume containing $1.5 \mathrm{mM} \mathrm{MgCl}, 50 \mathrm{mM} \mathrm{KCl}, 10$ $\mathrm{mM}$ TRIS/ $\mathrm{HCl}(\mathrm{pH} 8.4), 0.1 \%$ gelatine $(\mathrm{w} / \mathrm{v})$, $0.2 \mathrm{mM}$ dNTPs (Pharmacia, Uppsala, Sweden) and 2.5 U Taq-DNA-polymerase (Pharmacia). The reaction product $(10 \mu \mathrm{l})$ was amplified for a second time through 25 cycles using $50 \mathrm{pmol}$ of the nested primers ct03 and ct04 (primer annealing at $60^{\circ} \mathrm{C}$ ) with all other conditions remaining the same. For both outer as well as nested PCR two negative controls (sterile distilled water and synovial fluid not spiked with CT) were included, which were prepared together with the other samples. Amplified product $(10 \mu \mathrm{l})$ was visualised by electrophoresis in a $1.5 \%$ agarose gel and stained with ethidiumbromide. Correct identity of PCR products was validated by hybridisation with specific digoxigenin labelled DNA probes or direct DNA sequencing. No increased sensitivity was noted after hybridisation.

GENERATION OF PERIPHERAL BLOOD MONOCYTES (PBMO) PERSISTENTLY INFECTED WITH

CHLAMYDIA TRACHOMATIS

Persistent infection of PBMo with CT was induced as described. ${ }^{11}$ Briefly, peripheral blood monocytes were isolated from peripheral blood of healthy donors by Ficoll-Hypaque density gradient centrifugation followed by plastic adherence. PBMo were then infected with CT at a multiplicity of infection of 1 and incubated in growth medium (RPMI 1640 supplemented with fetal calf serum, $10 \% \mathrm{v} / \mathrm{v}$, L-glutamine $1 \% \mathrm{w} / \mathrm{v}$, vancomycin $0.1 \% \mathrm{w} / \mathrm{v}$, gentamcin $0.1 \% \mathrm{w} / \mathrm{v}$ ) at $37^{\circ} \mathrm{C}$ in an atmoshpere of carbon dioxide $5 \% \mathrm{v} / \mathrm{v}$. Seven days after infection monocytes were harvested. At this time monocytes do not contain any infective chlamydia, however by electron microscopy intracellularly persisting chlamydia can be demonstrated in about $10 \%$ of the PBMo. ${ }^{12}$ Persistently infected monocytes were then washed thoroughly three times in PBS. Monocytes were resuspended in $1 \mathrm{ml}$ PBS, counted and diluted serially 10 -fold (from $10^{4}$ to $10^{-2}$ monocytes per $\mathrm{ml}$ of synovial fluid) in synovial fluid from a patient with RA. Two negative controls with no monocytes added were included in each experiment. Four dilution series were processed by either method (3b) or (4b) and analysed by PCR.

Table 1 Cumulative ranking (CR) and sensitivity in EB/ml of methods (1), (2), (3a), and (4a)

\begin{tabular}{|c|c|c|c|c|c|c|c|c|}
\hline \multirow[b]{3}{*}{ Dilution series } & \multicolumn{2}{|l|}{ Method (1) } & \multicolumn{2}{|l|}{ Method (2) } & \multicolumn{2}{|l|}{ Method (3a) } & \multicolumn{2}{|l|}{ Method (4a) } \\
\hline & \multicolumn{2}{|c|}{ Washing in PBS } & \multicolumn{2}{|c|}{ Enzymatic digestion } & \multicolumn{2}{|c|}{ Phenol/chloroform } & \multicolumn{2}{|l|}{$Q I A E X$} \\
\hline & $\begin{array}{l}\text { Sensitivity in } \\
E B / m l\end{array}$ & Rank & $\begin{array}{l}\text { Sensitivity in } \\
E B / m l\end{array}$ & Rank & $\begin{array}{l}\text { Sensitivity in } \\
E B / m l\end{array}$ & Rank & $\begin{array}{l}\text { Sensitivity in } \\
E B / m l\end{array}$ & Rank \\
\hline 1 & 37 & 3 & 250 & 4 & 0.1 & 1 & 10 & 2 \\
\hline 2 & 37 & 3 & 250 & 4 & 1 & 1 & 10 & 2 \\
\hline 3 & 1200 & 4 & 250 & 3 & 0.1 & 1 & 1 & 2 \\
\hline 4 & 120 & 4 & 25 & 3 & 1 & 1 & 10 & 2 \\
\hline 5 & 1200 & 4 & 25 & 2 & 0.1 & 1 & 1000 & 3 \\
\hline median/CR & 120 & 18 & 250 & 16 & 0.1 & 5 & 10 & 11 \\
\hline
\end{tabular}


Table 2 Cumulative ranking (CR) and sensitivity in EB/ml of methods (3a), (3b), (4a), and (4b)

\begin{tabular}{|c|c|c|c|c|c|c|c|c|}
\hline \multirow[b]{3}{*}{ Dilution series } & \multicolumn{2}{|l|}{ Method (3a) } & \multicolumn{2}{|l|}{ Method (3b) } & \multicolumn{2}{|l|}{ Method (4a) } & \multicolumn{2}{|l|}{ Method (4b) } \\
\hline & \multicolumn{2}{|c|}{ Phenol/chloroform } & \multicolumn{2}{|c|}{$\begin{array}{l}\text { Phenol/chloroform } \\
+C T A B\end{array}$} & \multicolumn{2}{|l|}{$Q I A E X$} & \multicolumn{2}{|c|}{$Q I A E X+C T A B$} \\
\hline & $\begin{array}{l}\text { Sensitivity in } \\
E B / m l\end{array}$ & Rank & $\begin{array}{l}\text { Sensitivity in } \\
E B / m l\end{array}$ & Rank & $\begin{array}{l}\text { Sensitivity in } \\
E B / m l\end{array}$ & Rank & $\begin{array}{l}\text { Sensitivity in } \\
E B / m l\end{array}$ & Rank \\
\hline 1 & 1 & 3 & 0.01 & 1 & 10 & 4 & 0.01 & 1 \\
\hline 2 & 1 & 2 & 0.1 & 1 & 10 & 3 & 10 & 3 \\
\hline 3 & 1 & 2 & 0.1 & 1 & 10 & 4 & 1 & 2 \\
\hline median/CR & 1 & 7 & 0.1 & 3 & 10 & 11 & 1 & 6 \\
\hline
\end{tabular}

STATISTICAL ANALYSIS

Statistical analysis was performed by the Wilcoxon matched pairs signed rank test. A value of $p<0.05$ was defined significant. The lowest absolute concentration of $C$ trachomatis elementary bodies that could be detected was the basis for ranking. For each set of experiments cumulative ranking was calculated by adding the rank numbers of each method for all series tested. The sample preparation leading to the highest sensitivity of PCR was ranked " 1 ". No attempts were made to further define sensitivity by intermediate dilutions. Determination of the ratio of elementary bodies compared with IFU was performed by regression analysis.

\section{Results}

DETERMINATION OF MOMP POSITIVE PARTICLES PER IFU

Two randomly selected aliquots from the stock of purified elementary bodies were diluted to 5 , 20, 40, $80 \mathrm{IFU} / 10 \mu \mathrm{l}$. Three slides per dilution were analysed by immunofluorescence. On average 7.7 fluorescent particles corresponded to one IFU (slope $=7.7, r^{2}=0.82, \mathrm{p}<0.0001$ ) (fig 2). Because more than $95 \%$ of these fluorescent particles were elementary bodies (data not shown), they will be referred to as elementary bodies. The number of elementary bodies determined by fluorescence was used in the spiking experiments. The sensitivity of PCR depending on the different methods of sample preparation was then evaluated using serial 10-fold dilutions of these purified elementary bodies in synovial fluid.

SENSITIVITY OF PCR DEPENDING ON THE METHOD OF SAMPLE PREPARATION

In the first run the methods (1), (2), (3a), and (4a) were compared. Highest sensitivity (0.1 elementary body $/ \mathrm{ml}$ ) was achieved with method (3a) (cumulative ranking, $\mathrm{CR}=5$ ) followed by method (4a) $(\mathrm{CR}=11)$ with a sensitivity of 10 elementary bodies $/ \mathrm{ml}$. The sensitivities of method (2) $(\mathrm{CR}=16)$ and method (1) $(\mathrm{CR}=18)$ were at least 100 times lower with 250 elementary bodies/ml and 120 elementary bodies/ml respectively (table 1 ).

Method (3a) was significantly more sensitive than all other methods $(p<0.05)$. Method (4a) was significantly more sensitive than method (1) $(p<0.05)$ but did not differ significantly from method (2) (table 1).

In the second run the two most sensitive methods (3a) and (4a) were compared with their modifications including an additional CTAB extraction (method (3b) and (4b)).

Addition of CTAB to method (3a) and method (4a) increased sensitivity by nearly 10 -fold for both sample preparation methods (see table 2 for cumulative ranking and sensitivity).

In the third run method ( $3 b$ ) and (4b) were modified by the addition of hyaluronidase to method (4b) and omission of hyaluronidase

Table 3 Cumulative ranking (CR) and sensitivity in EB/ml of methods (3b), (3c), (4b), and (4c)

\begin{tabular}{|c|c|c|c|c|c|c|c|c|}
\hline \multirow[b]{3}{*}{ Dilution series } & \multicolumn{2}{|l|}{ Method (3b) } & \multicolumn{2}{|l|}{ Method (3c) } & \multicolumn{2}{|l|}{ Method (4b) } & \multicolumn{2}{|l|}{ Method (4c) } \\
\hline & \multicolumn{2}{|c|}{$\begin{array}{l}\text { Phenol/chloroform } \\
+C T A B\end{array}$} & \multicolumn{2}{|c|}{$\begin{array}{l}\text { Phenol/chloroform } \\
+C T A B-H y a l u r o n i d a s e\end{array}$} & \multicolumn{2}{|c|}{$Q I A E X+C T A B$} & \multicolumn{2}{|c|}{$\begin{array}{l}\text { QIAEX+CTAB } \\
+ \text { Hyaluronidase }\end{array}$} \\
\hline & $\begin{array}{l}\text { Sensitivity in } \\
E B / m l\end{array}$ & Rank & $\begin{array}{l}\text { Sensitivity in } \\
E B / m l\end{array}$ & Rank & $\begin{array}{l}\text { Sensitivity in } \\
E B / m l\end{array}$ & Rank & $\begin{array}{l}\text { Sensitivity in } \\
E B / m l\end{array}$ & Rank \\
\hline 1 & 0.01 & 1 & ir & nd & 1 & 2 & 10 & 3 \\
\hline 2 & 0.01 & 1 & ir & nd & 10 & 2 & 10 & 2 \\
\hline 3 & 0.01 & 1 & ir & nd & 10 & 2 & 100 & 3 \\
\hline median/CR & 0.01 & 3 & nd & nd & 10 & 6 & 10 & 8 \\
\hline
\end{tabular}

ir $=$ inconsistent results; $\mathrm{nd}=$ not determined.

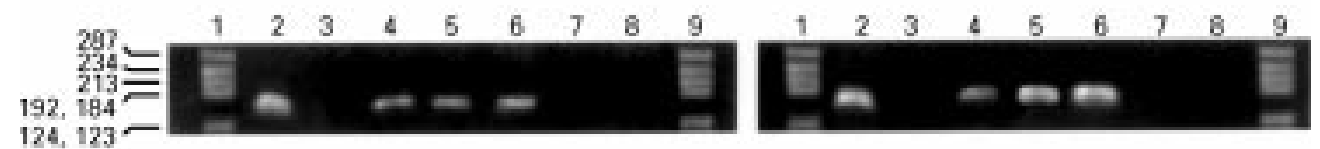

Figure 3 Electrophoresis of amplified DNA by nested PCR for serial 10-fold dilutions of persistently infected PBMo in synovial fluid. Lanes 1 and 9: molecular weight marker (pBR322 cleaved with HaeIII), lane 2: positive control (purified DNA of $C$ trachomatis), lanes 3 and 8: negative controls prepared together with the other samples (lane 3: distilled water, lane 8: synovial fluid from $R A$ patient), lanes 4, 5, 6, and 7:10-fold serial dilutions of persistently infected PBMo from $10^{2}$ to $10^{-1}$ PBMo per $m l$ of synovial fluid. Left panel: dilution series processed by method (3b). Right panel: dilution series processed by method $(4 b)$. 
pretreatment from method (3b) respectively. Addition of hyaluronidase (method (4c)) did not affect sensitivity of subsequent PCR. Omission of hyaluronidase pretreatment (method (3c)) imposed technical problems for pipetting, so that samples could not be processed reliably (table 3 ).

SENSITIVITY FOR THE DETECTION OF

INTRACELLULAR CHLAMYDIA TRACHOMATIS IN SYNOVIAL FLUID

To analyse whether the two optimised methods for preparation of synovial fluid (method (3b) and (4b)) were able to detect intracellular CT with high sensitivity, peripheral blood monocytes persistently infected with CT serially 10 -fold diluted in synovial fluid, were processed by either method (3b) or (4b) and analysed by PCR. Both methods allowed the detection of one infected monocyte per sample analysed (fig 3).

\section{Discussion}

The hallmark of reactive arthritis is that the arthritis eliciting bacteria persist intraarticularly in very low quantity but cannot be cultured from synovial fluid. ${ }^{2}{ }^{4}$ Initially immunofluorescence studies and RNA hybridisation of synovial specimens were performed demonstrating intra-articularly persisting $C$ trachomatis. ${ }^{2}{ }^{3}$ However, recently PCR has emerged as most promising tool in the diagnosis of CT induced arthritis. PCR allows the detection of theoretically one organism per sample and has proved to be effective in the search for arthritic eliciting bacteria in synovial fluid and membrane.

Sensitivity of PCR is the result of sample preparation and the PCR itself. To our knowledge no systematic comparison of different sample preparations of synovial fluid for PCR has been published.

In this study synovial fluid spiked with defined numbers of purified CT elementary bodies were processed using different sample preparations for synovial fluid and then analysed by a CT specific PCR. This approach was chosen because firstly CT represents one of the most common causes of reactive arthritis, secondly using synovial fluid samples spiked with defined numbers of CT will enable other laboratories to directly compare the sensitivity of their method of synovial fluid preparation with those analysed in this study, and thirdly by sytematic modification and comparsion, a highly sensitive method of sample preparation feasible for routine diagnosis could be developed.

In our analysis we initially compared three methods recently published (methods (1), ${ }^{13}$ $(2),{ }^{5}$ and $\left.(3 a)^{9}\right)$ for preparation of synovial fluid with a method developed in our laboratory (method (4a)). Both methods (3a and 4a) including additional DNA extraction were significantly more sensitive than method (1), which only includes washing of the synovial fluid pellet or method (2), which additionally includes enzymatic digestion.

Different modifications of the phenol/ chloroform extraction method (method (3a)) have been used successfully by several investigators to detect bacterial organisms in the joint (for review see Wollenhaupt et $a l^{14}$ ). Method (1) has also been used for analysis of synovial fluid by CT specific PCR, however no CT could be detected in synovial fluid in this study. ${ }^{13}$ From our data these differences can be explained by the high sensitivity of method (3a) and the low sensitivity of method (1), respectively.

The addition of CTAB to sample processing in method (3a) and (4a) increased sensitivity 10-fold. At high $\mathrm{NaCl}$ concentration CTAB allows precipitation of polysaccharides and proteins, both of them can inhibit PCR. CTAB has been described to improve the analysis of bronchoalveolar lavage by $C$ pneumoniae specific PCR and was successfully used in the preparation of synovial fluid for PCR. ${ }^{15}{ }^{16}$ Both, bronchoalveolar lavage as well as synovial fluid contain glycoproteins with acidic polysaccharides. The precipitation of these PCR inhibitors by CTAB probably explains the increase in sensitivity.

The effect of hyaluronidase treatment was then analysed. The addition of hyaluronidase before CTAB-QIAEX extraction did not improve sensitivity. Hyaluronidase, however, was necessary before the phenol/chloroformCTAB extraction to obtain reproducible results.

In the inflamed joint chlamydia is persisting intracellularly in monocytes. To analyse whether the two optimised sample preparations developed in this study would allow high sensitivity in the detection of intracellular chlamydia, persistingly infected PBMo were diluted in synovial fluid and analysed by method (3b) and (4b). Ultrastructural and molecular analyses of the persistence of chlamydia in these monocytes demonstrated striking ressemblance compared with the altered state of the chlamydia in the joint. ${ }^{12}$ Both methods allowed the detection of a single persistingly infected monocyte per sample. Obviously both methods allowed not only the detection of chlamydial elementary bodies but also the detection of intracellularly persisting chlamydia as they are present in the joint.

In summary this study demonstrates the importance of optimised sample preparation before PCR. Depending on the sample preparation used before PCR, the sensitivity could be increased by more than 100-fold. Methods including specific DNA extraction and precipitation of PCR inhibitors by CTAB led to much higher sensitivity. Internationally standardised sample preparation as well as standardised PCR protocols will be crucial for diagnostic reliability and validity of CT induced arthritis. With regard to the low quantity of CT present in the joint, optimised sample preparation should be used. In experienced hands the more complicated and laborious phenol/chloroform + CTAB method allows highest sensitivity and should be the method of choice for research applications. For routine diagnosis we would recommend the CTAB-QIAEX method because it is simple, fast, and less toxic than the more complicated phenol/chloroform + CTAB method. Although not tested in this study the 
QIAEX-CTAB method should also be feasible for PCRs specific for other bacteria because a bias for DNA only of certain bacteria seems most unlikely.

Funding: this study was supported by the Deutsche Forschungsgemeinschaft, grant number KU 1182/1-1, and the Bundesministerium für Bildung und Forschung, grant number 01VM9305.

1 Schachter J. Chlamydial infections. West J Med 1990;153:523-34.

2 Keat A, Dixey J, Sonnex C, Thomas B, Osborne M, TaylorRobinson D. Chlamydia trachomatis and reactive arthritis:

the missing link. Lancet 1987;i:72-4.
3 Hammer M, Nettelnbreker E, Hopf S, Schmitz E, Poerschke K, Zeidler H. Chlamydial rRNA in the joints of patients with Chlamydia trachomatis induced arthritis and undifferentiated arthritis. Clin Exp Rheumatol 1992;10 63-6.

4 Nanagara R, Li F, Beutler A, Hudson A, Schumacher HR Jr. Alteration of Chlamydia trachomatis biologic behavior in synovial membranes. Suppression of surface antigen production in reactive arthritis and Reiter's syndrome. production in reactive arthritis and

5 Bas S, Griffais R, Kvien TK, Glennas A, Melby K, Vischer TL. Amplification of plasmid and chromosome Chlamydia DNA in synovial fluid of patients with reactive arthritis and DNA in synovial fluid of patients with reactive arthritis and undifferentiated seronegative

6 Hudson AP, Gerard HC, Branigan PJ, Schumacher HR. Viability of inapparent synovial Chlamydia trachomatis in patients with Reiter's syndrome (RS)/reactive arthritis (ReA). Arthritis Rheum 1995;40 (suppl);S393.

7 Beutler, AM, Hudson AP, Whittum-Hudson JA, Salameh WA, Gerard HC, Branigan PJ, et al. Chlamydia trachomatis can persist in joint tissue after antibiotic treatment in chronic Reiter's syndrome/reactive arthritis. J Clin Rheumatol 1997;3:125-30. 8 Kuipers JG, Scharmann K, Wollenhaupt J, Nettelnbreker E,
Hopf S, Zeidler H. Sensitivities of PCR, MicroTrak, Hopf S, Zeidler H. Sensitivities of PCR, MicroTrak,
ChlamydiaEIa, IDEIA and PACE 2 for purified Chlamydia ChlamydiaEIa, IDEIA and PACE 2 for purified Chlamydia trachomatis elementary bodies in urine, peripheral blood, peripheral blood leukocytes

9 Liebling MR, Nishio MJ, Rodrigues A, Sigal LH, Jin T, Louie JS. The polymerase chain reaction for the detection of borrelia burgdorferi in human body fluids. Arthritis Rheum 1993;36:665-74.

10 Nikkari S, Möttönen T, Saario R, Yli-Kerttula U, LerisaloRepo M, Laitio P, et al. Demonstration of salmonella DNA in the synovial fluid in reactive arthritis. Arthritis Rheum 1996;39 (suppl):S185.

11 Schmitz E, Nettelnbreker E, Zeidler H, Hammer M, Manor Schmitz E, Nettelnbreker E, Zeidler H, Hammer M, Manor
E, Wollenhaupt J. Intracellular persistence of chlamydial major outer-membrane protein, lipopolysaccharide and ribosomal RNA after non-productive infection of human Monocytes with Chlamydia tra

2 Köhler L, Nettelnbreker E, Hudson AP, Ott N, Gerard HC, Branigan PJ, et al. Ultrastructural and molecular analyses of the persistence of Chlamydia trachomatis (serovar $\mathrm{K}$ ) in human monocytes. Microb Pathog 1997;22:133-42.

13 Poole S, Highton J, Wilkins RJ, Lamont IL. A search for Chlamydia trachomatis in synovial fluids from patients with reactive arthritis using the polymerase chain reaction and antigen detection methods. Br J Rheumatol 1992;31: $31-4$.

14 Wollenhaupt J, Schnarr S, Kuipers JG. Bacterial antigens in reactive arthritis and spondarthritis. Rational use of laboratory testing in diagnosis and follow-up. Baillieres Clin Rheumatol (in press).

15 Maas M, Dalhoff K. Comparison of sample preparation methods for detection of Chlamydia pneumoniae in bronchoalveolar lavage fluid by PCR. J Clin Microbiol 1994;32: 2616-19.

16 Schaeverbeke T, Clerc $M$, Lequen L, Bebear CM, Bannwarth B, Bebear C, et al. Screening of synovial fluids from patients with various inflammatory arthritides for the presence of mycoplasma fermentans. Arthritis Rheum 1997;40 (suppl):S271. 